

\section{Mídias personalizadas versus mídias generalistas: entrevista com Dominique Wolton}

\section{Custom medias versus general medias: interview with Dominique Wolton}

\section{Karine Ruy ${ }^{1} \widetilde{3}$, Mateus Vilela ${ }^{2}{ }^{3}$}

Tradução e transcrição: luri Furukita Baptista ${ }^{3}$
O sociólogo francês Dominique Wolton é reconhecido por investigar os desafios da comunicação em tempos de inflação de ferramentas midiáticas e informacionais. Autor de mais de 30 livros, entre eles, títulos lançados no Brasil, como Internet, e depois? - Uma teoria crítica das novas mídias e Informar não é comunicar, Wolton foi um dos palestrantes do seminário comemorativo aos 20 anos do Programa de Pós-Graduação em Comunicação da PUCRS. Nesta entrevista, o diretor de pesquisa do Centro Nacional da Pesquisa Científica (CNRS), fala sobre o status contemporâneo da comunicação e as possibilidades de diálogo e diversidade cultural no ambiente digital.

Sessões do Imaginário - O senhor acredita que as redes sociais constituem um espaço de comunicação ou simplesmente são locais de circulação de informação?

Dominique Wolton - Sim, pois bem, certamente existe comunicação nas redes sociais. Porém é uma comunicação limitada àqueles a quem eu me direciono. Ela é muito útil, claro, mas eu devo dizer que é uma comunicação restrita a grupos de interesses, para encontrar a heterogeneidade da sociedade é preciso sair das redes sociais.

\section{ENTREVISTA}


SI - O senhor vê algum indício de que a heterogeneidade, a multiplicidade e a diversidade possam vir a ocupar esse espaço digital, a potencializar o diálogo com o diferente e, não apenas, com os grupos e comunidades já existentes?

DW - Eu não tenho certeza, porque eu penso que as pessoas gostam das redes sociais para se encontrar entre si. Claro, por mais que possam se encontrar com o diferente, eu acredito que existe uma dualidade entre as redes sociais - que são rápidas, ágeis e interativas - e a mídia de massa - que ainda se mantém à escola da alteridade. Então, eu vejo que uma coexistência dessas duas formas funciona bem e que não é verdade que as pessoas que estão nas redes sociais possam dispensar os jornais, os livros e a televisão. Precisamos desses dois modelos, de uma aproximação de ambos.

SI - Qual a sua perspectiva para as indústrias da comunicação e do entretenimento diante da cultura do gratuito na sociedade digital?

DW - Bem, em termos econômicos, sou certamente da opinião de que a internet precisa de regulamentação efetiva. Acredito que caiba aos Estados encontrarem formas para que os internautas paguem por aquilo que consomem. Caso contrário, é uma situação injusta e perversa. Se colocarmos a questão do ponto de vista político, já existem regulamentações, acordos etc.

SI - A TV é o único modo de criar um laço social entre a massa anônima ou as redes sociais também podem criar essas ligações com ferramentas como as hashtags?

DW - Sim, está claro que as redes sociais também geram laços sociais, mas onde elas os geram? Dentro de um limite, dentro do senso de que o protagonista possui a mesma cultura daquilo que procura. Como o princípio das ligações sociais nas redes sociais são as semelhanças, mesmo que essa semelhança se abra, ela delimita. É por isso que a abertura nas redes sociais é boa, é necessária, é útil, mas necessita da complementação da mídia que eu chamo de "mídia de oferta", [em oposição à mídia baseada na busca] dos impressos, da televisão, do rádio. Precisamos desses dois modelos.
SI - Perante o crescimento da televisão fechada e dos conteúdos cada vez mais focados em nichos, a coesão social e a identificação de público que o senhor identifica na televisão aberta passarão para televisão fechada?

DW - Sim, é verdade que a dinâmica da televisão temática, da televisão por cabo, se desenvolveu da mídia generalista. Contudo, há uma diferença elementar, pois na mídia generalista existe uma multidão que não

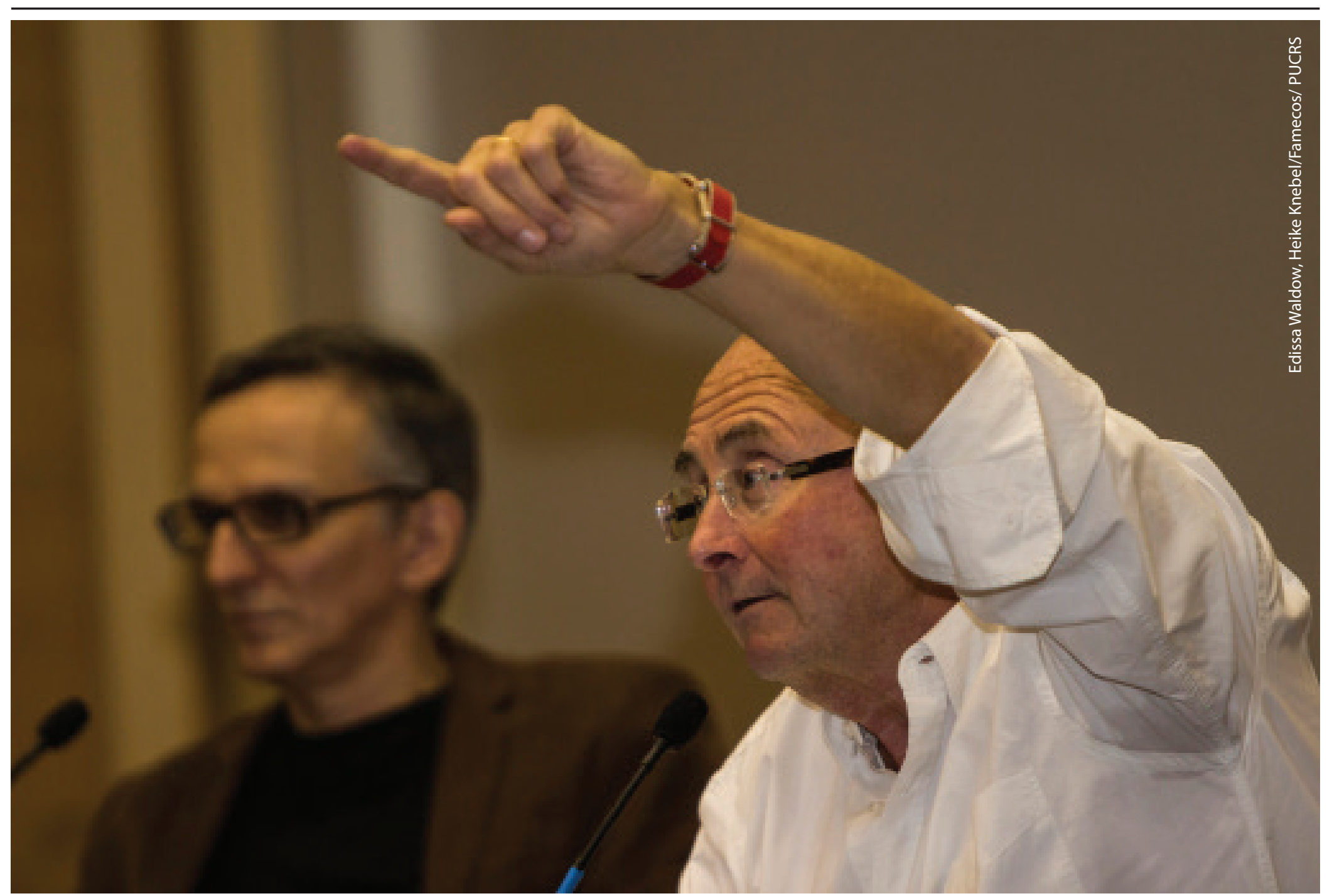

06 PORTO ALEGRE | v. 19 | n. 32 | 2014 | pp. 05-07 Sessões do Imaginário 
se encontra na mídia temática, ou na internet. Assim, se eu retiro a mídia generalista, haverá uma crise de consciência política porque falta um espaço para comutação, um espaço que seja dividido por todos. Como eu digo, lidar com o temático é fácil, com o generalista é difícil.

SI - Ainda podemos falar em solidões interativas diante das comunidades virtuais?

DW - Sim, podemos. Podemos porque a solidão interativa existe dentro dessas comunidades. O que é o progresso na vida? É a constante confrontação com situações e experiências que são diferentes. Mantenha tudo: as mesmas coisas, o mesmo bairro, a mesma casa, o mesmo casal etc. Oras, fica tudo na mesma. Então, eu não digo que os meios de massa são perfeitamente formidáveis, de forma alguma! Contudo, existem dois aspectos interessantes na mídia de massa: é o lugar de oferta, em oposição à cultura do conteúdo por demanda, e o lugar de todos os públicos. Essas não são perspectivas da internet ou da televisão comunitária. $O$ problema de hoje não é a complementariedade desses diferentes meios, o problema de hoje é que as pessoas fãs da internet acham que são mais inteligentes, mais avançadas, mais modernas que as pessoas fãs da imprensa escrita e da televisão. Isso é estúpido. Em francês, temos um ditado: "vassoura nova, vassoura boa". Mas não só porque é nova que é melhor.
Referências

WOLTON, Dominique. Informar não é comunicar. Por-

to Alegre: Sulina, 2010.

Internet, e depois? - Uma teoria crítica das novas mídias. Porto Alegre: Sulina, 2003.

Notas

1 Doutoranda do Programa de Pós-Graduação em Comunicação Social da Pontifícia Universidade Católica do Rio Grande do Sul (PPGCOM/PUCRS - Av. Ipiranga, 6681 Prédio 7, Sala 319, CEP: 90619-900, Porto Alegre/RS, Brasil). Bolsista CAPES. E-mail: karineruy@gmail.com.

2 Doutorando do Programa de Pós-Graduação em Comunicação Social da Pontifícia Universidade Católica do Rio Grande do Sul (PPGCOM/PUCRS - Av. I Iiranga, 6681 - Prédio 7, Sala 319, CEP: 90619-900, Porto Alegre/RS, Brasil). Bolsista CAPES. E-mail: mateusdvilela@gmail.com.

3 Mestrando do Programa de Pós-Graduação em Comunicação da Pontifícia Universidade Católica do Rio Grande do Sul (PPGCOM/PUCRS - Av. Ipiranga, 6681 - Prédio 7, Sala 319, CEP: 90619-900, Porto Alegre/RS, Brasil). E-mail: iuri. baptista@acad.pucrs.br. 